\title{
PROTOCOLO CLÍNICO DE ATENDIMENTO INTEGRAL À CRIANÇAS E ADOLESCENTES
}

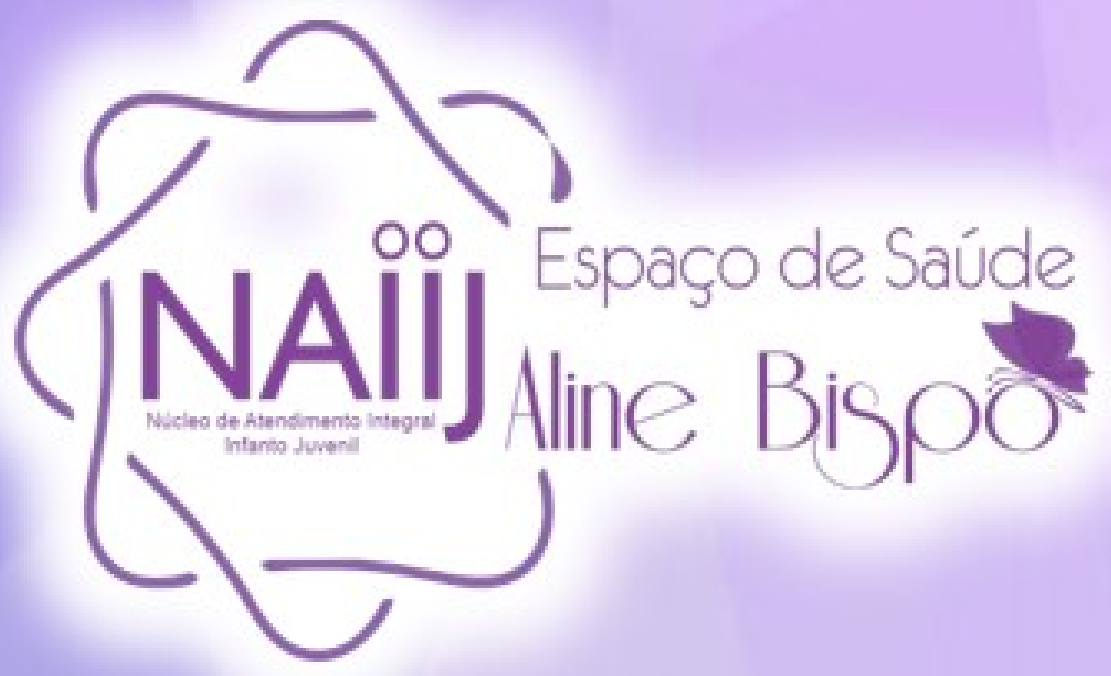

Aline Bispo

Lucimauro Palles

Uelinton Meira

foñema 2

Grafema 



\section{PROTOCOLO CLÍNICO DE ATENDIMENTO INTEGRAL À CRIANÇAS E ADOLESCENTES}

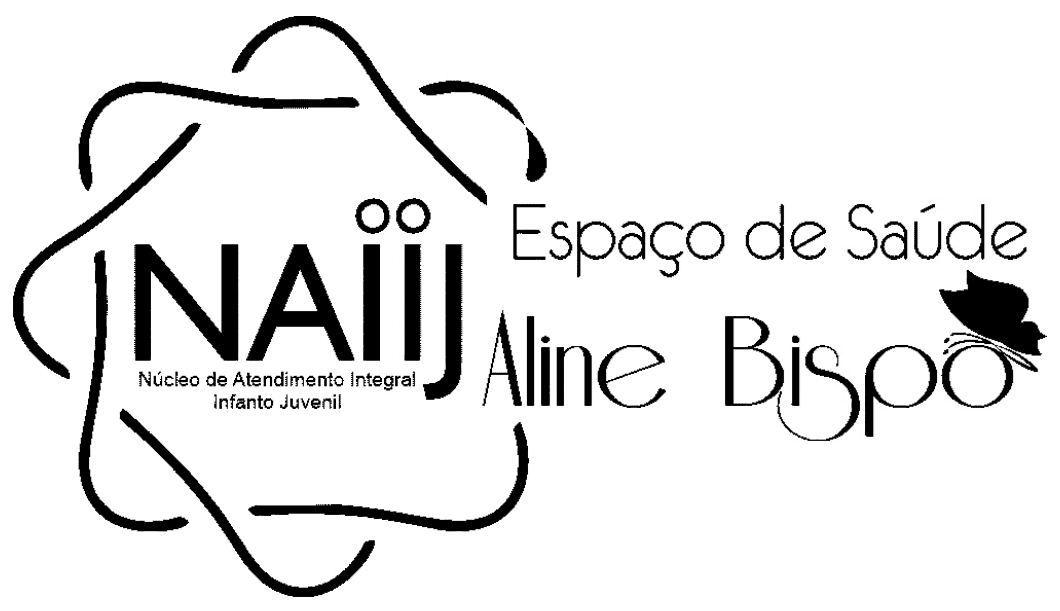

Aline Bispo Lucimauro Palles Uelinton Neris 
Nenhuma parte desta publicação pode ser reproduzida ou transmitida em qualquer forma ou por qualquer meio, eletrônica ou mecanicamente, exceto nos termos permitidos pela lei, sem a autorização prévia e expressa do titular do Espaço de Saúde Aline Bispo. 
Dados Internacionais de Catalogaçâo na Publicação (CIP) (Câmara Brasileira do Livro, SP, Brasil)

Protocolo clínico de atendimento integral à crianças e adolescentes / organização Aline Bispo, Lucimauro Palles da Silva, Uelinton Meira Neris...- 1. ed. Vitória da Conquista, BA: Espaço de Saúde, 2021.

Bibliografia.

I S B N

1. Protocolos médicos 2. Saúde Integral I. Bispo, Aline. II. Silva, Lucimauro Palles da. III. Neris, Uelinton Meira. 


\title{
CONSELHO EDITORIAL E CIENTÍFICO
}

\author{
Aline Bispo \\ Juliana Barros \\ Lucimauro Palles da Silva \\ Ronei Guaresi \\ Uelinton Meira Neris
}

Este livro foi avaliado e aprovado por pareceristas ad hoc 


\section{LISTA DE ABREVIATURAS E SIGLAS}

ESAB Espaço de Saúde Aline Bispo

ESAB24h Aplicativo de interação clínica e família

EPA Escola de Pais e aplicadores

NAlIJ Núcleo de Acompanhamento Integral Infanto Juvenil

PICS Práticas Integrativas Complementares

PTS Projeto Terapêutico Singular 


\section{SUMÁRIO}

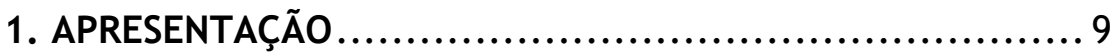

2. NATUREZA E OBJETIVOS DO PROTOCOLO ...................11

3. PRÁTICAS INTEGRATIVAS COMPLEMENTARES...............12

4. APLICAÇÃO DO PROTOCOLO .............................13

5. ESPECIALIDADES TERAPEUTICAS ........................14

6. ESPECIALIDADES CLÍNICAS .............................17

7. MONITORAMENTO COM ESTUDOS DE CASOS ...............22

8. DEVOLUTIVA PARA AS FAMÍLIAS .........................23

9. ESCOLA DE PAIS E APLICADORES (EPA/ESAB) ..............24

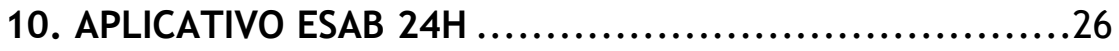

REFERÊNCIAS ...........................................27

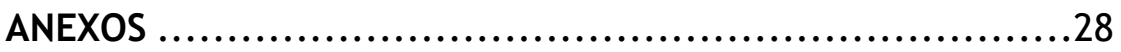

Entrevista de Acolhimento ..............................28

Termo de Compromisso dos pais e responsáveis ..............31 


\section{APRESENTAÇÃO}

$O$ atendimento a crianças e adolescentes sempre foi uma prioridade no Espaço de Saúde Aline Bispo (ESAB) que acontecia no mesmo espaço do atendimento de adultos. Com o tempo, foi necessário pensar em um espaço especial para acolhimento, atendimento $e$ acompanhamento desse público infanto juvenil. Pensando em atender essa demanda local, foi implantado o Núcleo de Acompanhamento Integral Infanto-juvenil (NAIIJ/ESAB) que integra os saberes $e$ compartilha boas práticas terapeuticas das áreas de arteterapia, natação, hidroginástica, funcional kids, musicoterapia e pet-terapia que são indicadas para todas as crianças e adolescentes, em especial nesse "novo normal" que exige uma readaptação de todos em especial das crianças e adolescentes.

Quando o paciente apresenta alguma dificuldade específica podem ser necessárias intervenções de escopo clínico que o NAIIJ/ESAB dispõe das especialidades de psicologia, psicopedagogia, neuropsicologia, fonoaudiologia, psicomotricidade, fisioterapia com pedia suit, nutrição, equoterpia e terapia ocupacional.

O presente documento apresenta orientações aos profissionais e aplicadores que podem ser pais ou 
estudantes de graduação selecionados pela Coordenação do NAIIJIESAB que irão auxiliar na melhora da performance dos pacientes no sentido de ampliar o repertório cognitivo e socioemocional dos pacientes.

$\mathrm{Na}$ busca de manter a parceria com as famílias, os pais elou responsáveis terão a possibilidade de receberem um retorno em atendimento e documento escrito, quanto a evolução terapeutica dos pacientes pelo período de 03 (três) meses conforme resultados dos estudos de casos que serão momentos de diálogos entre os profissionais que realizam o acompanhamento dos pacientes produzindo o Projeto Terapêtico Singular (PTS),é elaborado de forma conjunta tendo em vista as peculiaridades de cada paciente.

Esperamos que esse segundo Protocolo colabore na manutenção de saúde integral de crianças e adolescentes realizados por profissionais das especialidades terapeuticas e clínicas para que os pacientes tenham seu desenvolvimento integral nas dimensões física, mental, interrelacional e sociomabiental.

Aline Bispo e Equipe. 


\section{NATUREZA E OBJETIVOS DO PROTOCOLO}

A integralidade é um conceito que pode ser considerado polissêmico, ou seja, com muitos sentidos que a ele podem ser atribuídos. Esse protocolo considera uma definição da integralidade a partir das necessidades de saúde que se apresentam para os serviços e saúde, e que traz a integralidade da atenção como composta por duas dimensões: a "integralidade focalizada" e a "integralidade ampliada" (CECÍLIO, 2001).

A dimensão "integralidade focalizada", exercita-se no momento do encontro entre trabalhadores de saúde e sujeitos que demandam cuidado, sendo o resultado da articulação de vários saberes de uma equipe multiprofissional no cotidiano de um serviço de saúde singular. A segunda dimensão, a "integralidade ampliada", acredita na articulação de vários serviços, equipamentos sociais e de saúde, tecnologias e profissionais de saúde e de uma articulação dialética e complementar entre a integralidade conseguida na relação de cuidado com cada profissional, no contexto de uma equipe, e de uma rede de serviços de saúde (CECÍLIO, 2001).

Esse Protocolo contempla o atendimento baseado nas Práticas Integrativas Complementares (PICS) como recursos que tem cunho terapeutico e são bastante utilizadas no contexto clínico. Além das PICS, quando necessárias são indicadas as especiliadades clínicas que podem auxiliar e intervierem junto ao paciente para responder a demandas específicas. 


\section{PRÁTICAS INTEGRATIVAS COMPLEMENTARES}

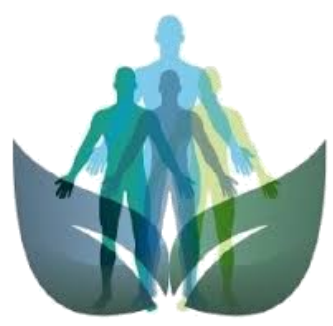

As Práticas Integrativas e Complementares em Saúde (PICS) são recursos terapêuticos que buscam a prevenção de doenças e a recuperação da saúde, com ênfase na escuta acolhedora, no desenvolvimento do vínculo terapêutico e na integração do ser humano com o meio ambiente e a sociedade.

As práticas foram institucionalizadas por meio da Política Nacional de Práticas Integrativas e Complementares, dentre as quais podemos citar: acupuntura, homeopatia, arteterapia, dança circular, meditação, Musicoterapia, naturopatia, osteopatia, quiropraxia, reflexoterapia, reiki, yoga, aromaterapia, bioenergética, constelação familiar, cromoterapia, geoterapia, hipnoterapia, ozonioterapia e terapia de florais.

São práticas transversais e favorecem uma visão ampliada do processo saúde/doença e da promoção global do cuidado humano, especialmente do autocuidado. As indicações são embasados no indivíduo como um todo, considerando-o em seus vários aspectos: físico, psíquico, emocional e social.

Destaca-se que seu uso aumenta a resolutividade a partir da integração - ao modelo convencional de cuidado de racionalidades com olhar e atuação mais ampliados, agindo de forma integrada e/ou complementar no diagnóstico, na avaliação e no cuidado. 


\section{APLICAÇÃO DO PROTOCOLO}

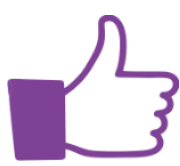

Os profissionais deverão observar as seguintes orientações para acolhimento de pacientes novos e que estão em acompanhamento no ESAB.

I. Antes de receber o paciente, será realizada uma entrevista de acolhimento do paciente que deverão ser preenichos os dados conforme as demandas de cada criança e/ou adolescente que busca pelos serviços de caráter terapeutico ou clínico no NAIIJ/ESAB (anexo 1).

II. Em seguinda será agendando um atendimento com os pais do paciente pela Coordenação do NAllJ/ESAB que irá apresentar o presente protocolo aos pais com ênfase nas potencialidades do paciente destacando as especialidades terapeuticas e se necessário as especialidades clínicas.

III. Após 03 (três) meses os profissionais que acompanham os pacientes irão se encontrar para um diálogo mediado pela Coordenação no NAIIJ/ESAB no sentido de conhecer os aspectos observados e sua evolução terapeutica, devendo para tanto fazer uma avaliação qualitativa das potencialidades e limites de cada paciente.

IV. Após o Estudo de Caso, os pais e/ou responsáveis serão chamados no ESAB para devolutiva da evolução qualitativa de seus filhos. Nessa oportunidade os pais terão espaço para pontuar possíveis alterações que auxiliarão a melhora nas práticas terapeuticas.

V. Caso os pais e/ou resposnáveis necessite falar com os profisisonais antes do momento de socialização deverá sinalizar a recepção do NAllJ/ESAB para o prévio agendamento evitando transtornos e atrasos nos atendimentos. 


\section{ESPECIALIDADES TERAPEUTICAS}

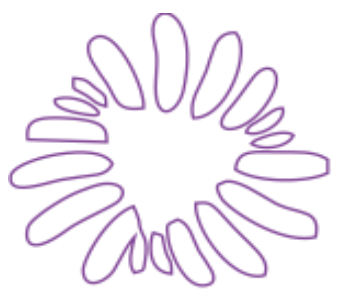

\section{Arteterapia}

A arteterapia ajuda a potencializar as capacidades intelectuais dos pacientes, com ela é possível expressar os sentimentos internos, dando vida e cor a eles, sendo uma ótima contribuição para resolver certos problemas emocionais.

Os principais tipos de arteterapia aplicados são: arte com os dedos, pintar com os pés, esculturas com material reciclável e desenhos na areia. A arteterapia ajuda no autoconhecimento, podendo ser uma forma de melhorar a autoconfiança e aumentar a autoestima.

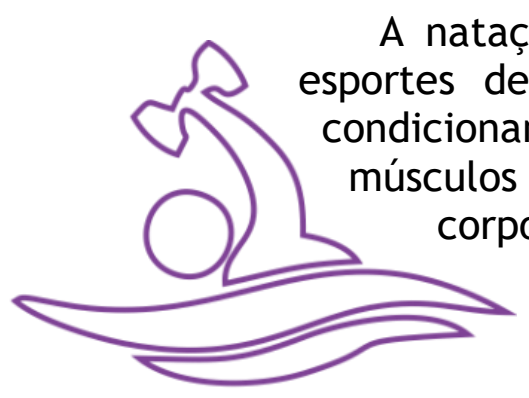

A natação e hidroginástica por serem esportes de baixo impacto, melhoram 0 condicionamento físico, fortalecem os músculos e articulações e não desgasta o corpo, são consideradas atividades completas com um baixo risco de ferimentos, pois os exercícios são realizados no aconchego da água. Suas Natação e Hidroginástica práticas trazem melhora para o sistema imunológico, ajudam no quesito sobrevivência, auxiliam no desenvolvimento cognitivo, favorecem noites de sono mais tranquilas, aumentam o apetite, a autoconfiança e cooperam com o desenvolvimento social. A hidroginástica também melhora no condicionamento cardiovascular e força muscular e circulação, colabora no como controle de fatores de risco para doenças crônicas como diabetes, cardiopatias e depressão. 
A Educação Física proporciona aos pacientes uma diversidade de experiências através de situações nas quais elas possam criar, inventar, descobrir movimentos novos, reelaborar conceitos e ideias sobre o movimento e suas ações. Colabora também na formação social dos pacientes, através de jogos e brincadeiras os alunos podem interagir e se socializar, objetivando melhorar o desenvolvimento corporal influenciando na aprendizagem, afetividade e sociabilidade.

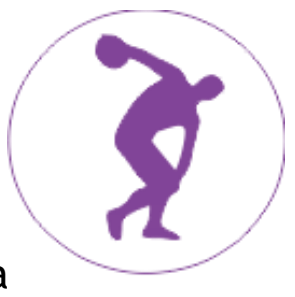

Funcional

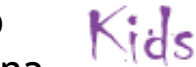

A musicoterapia é uma abordagem terapêutica que deve ser conduzida por profissional habilitado com formação específico

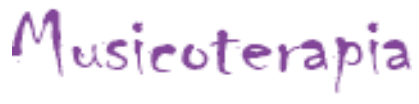
que utiliza sons nas intervenções com os pacientes, através do uso de músicas que estão imersas na sua cultura e contexto com a utilização de instrumentos musicais ou sons produzidos por elas, como gritos, tiques vocais ou quaisquer produções. A música ajuda no desenvolvimento porque os sons estimulam a audição e a fala, as harmonias ajudam no desenvolvimento (2) intelectual e motor, colabora na facilidade de aprender novas palavras de pronúncias mais corretas, melhora no desenvolvimento afetiva e no desenvolvimento da coordenação motora. 


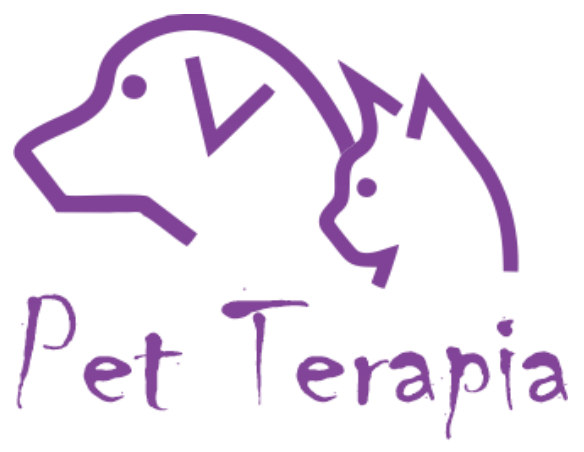

A Terapia Assistida por Animais (TAA) ou Pet-terapia desperta para a socialização, diminui o estresse, aumenta a autoestima, a confiança, motivação, descontração e entretenimento para as crianças e adolescentes. A atividade é essencial para deixar o ambiente mais acolhedor e leve. Os principais fundamentos da pet-terapia estão ligados à parte emocional, concentração e socialização, com destaque para benefícios como 0 aumento do contato com a realidade, o foco da atenção aplicada em atividades específicas, o favorecimento de estados como positividade, alegria e amor, a facilidade em colaborar com o terapeuta, o estímulo ao contato social e à conversação, a troca de carinho físico com o animal, o desenvolvimento de empatia, aceitação e confiança, o aprendizado sobre responsabilidade e cuidado com o outro, a distração, diversão e brincadeiras positivas que diminuem a sensação de isolamento. 


\section{ESPECIALIDADES CLÍNICAS}

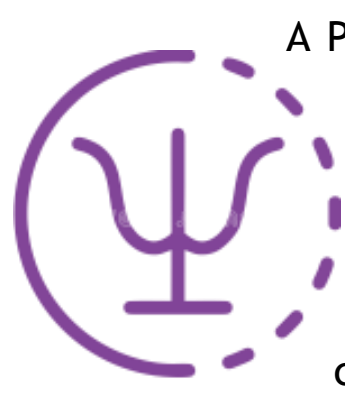

A Psicologia acompanha os processos mentais característicos de cada etapa do desenvolvimento, objetivando trabalhar com cuidado as emoções, as percepções e os aprendizados, respeitando a personalidade do paciente, buscando compreender as formas de falar, sentir, Psicologia gerar conhecimento, criar imagens e construir sentidos para o mundo ao redor do paciente favorecendo que o mesmo vivencie as etapas do seu desenvolvimento, melhorando sua independência $e$ autoconfiança.

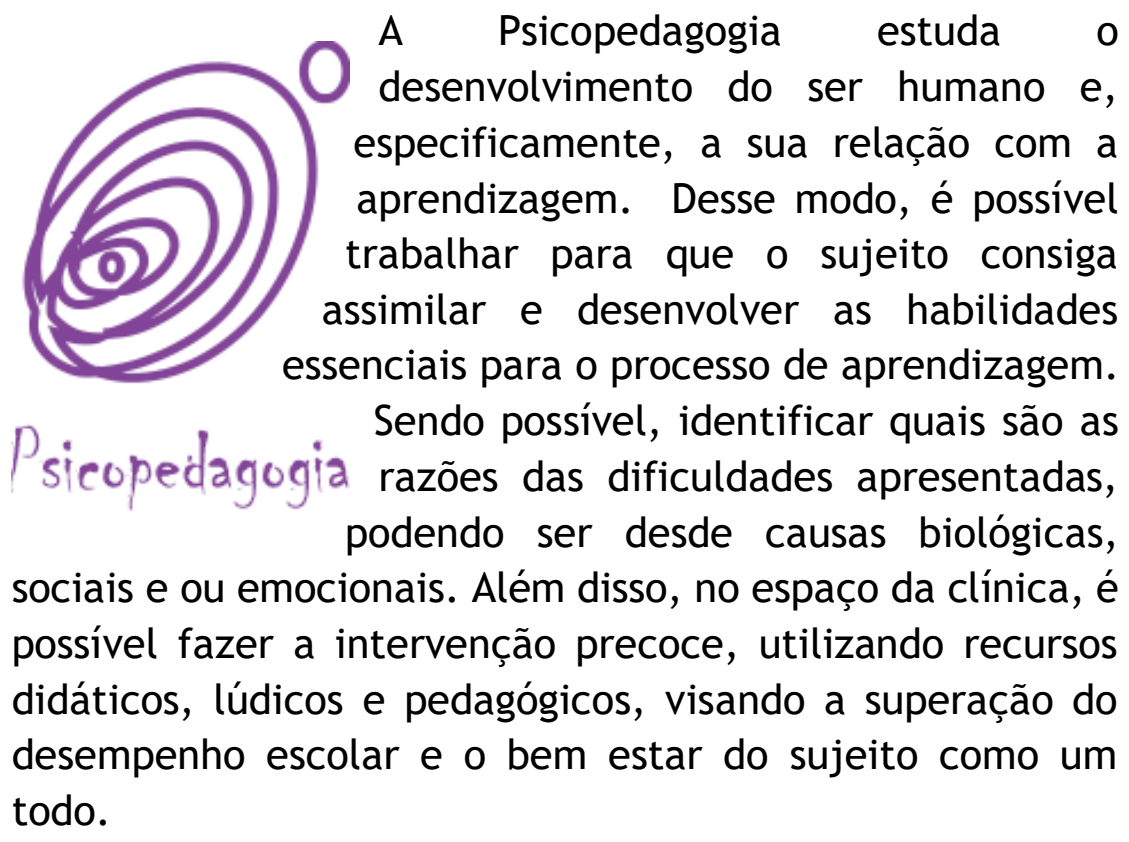




\section{Psicomotricidade Psicomotricidade}

busca compreender as influências entre o

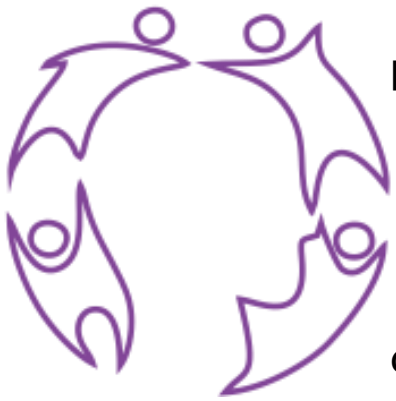

psiquismo e a motricidade, dedica-se ao estudo do ser humano por meio de seu movimento compreendendo que o corpo é a origem da aquisição de habilidades cognitivas, afetivas e orgânicas. Engloba a relação existente entre pensamento, emoção e ação e auxilia o desenvolvimento global do paciente por meio de seus movimentos, ajudando a evitar distúrbios trabalhando os aspectos motor, cognitivo e afetivo.

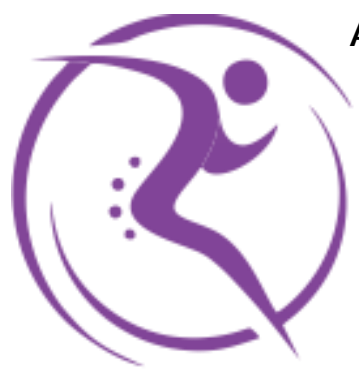

A fisioterapia traz inúmeros benefícios para o paciente garantindo um desenvolvimento sadio e um bom crescimento, evitando que limitações e dificuldades tragam sequelas mais graves ao longo dos anos ou na vida adulta. Sua Fisioterapia at atuação acontece de maneira preventiva, evitando que problemas e vícios posturais ou questões respiratórias. Em pacientes com algum transtorno do neurodesenvolvimento pode ajudar a se tornar mais independente. 


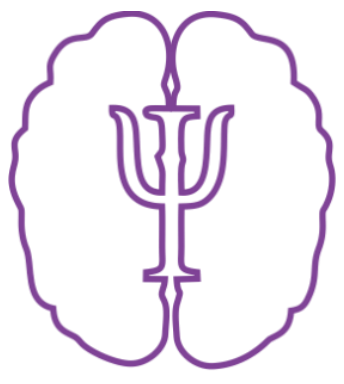

A Neuropsicologia é uma especialidade dentro da Psicologia que é considerada como ciência que estuda de modo aprofundado sobre 0 funcionamento cerebral, os processos cognitivos superiores e suas relações com Neuropsicologia o comportamento humano. A avaliação neuropsicológica é um exame diagnóstico que tem o objetivo de avaliar as funções cognitivas preservadas do paciente e se há algum prejuízo nestas áreas. 0 principal enfoque da neuropsicologia é o desenvolvimento de uma ciência do comportamento humano baseada no funcionamento do cérebro.

Fonoaudiologia

A fonoaudiologia é a área que atua na linguagem proporcionando o (《is) desenvolvimento das habilidades da criança e sua inclusão social por meio do estudo, avaliação, diagnóstico e terapia. Favorece 0 tratamento adequado aos transtornos relacionados à comunicação oral e escrita. Colabora também na sucção do bebê, evitando a pega incorreta e fissuras das mamas para uma amamentação eficiente. Orienta nos cuidados relacionados à audição, articulação da fala, voz, linguagem oral, leitura e escrita. 


\section{Nutrição}

A nutrição identifica as necessidades de cada paciente, proporcionando uma orientação individualizada. Os aspectos mais importantes para uma alimentação saudável são: introdução alimentar, alimentação pré-escolar e escolar, perda ou ganho de peso repentino, doenças como diabetes, intolerância à lactose, transtornos gastrointestinais, doença celíaca, problemas na tireoide, dúvidas em relação à alimentação, sinais de deficiência nutricional, nutrição esportiva, orientação para ganho de massa mascular e seletividade alimentar.

\section{Equoterapia}

A equoterapia é um método

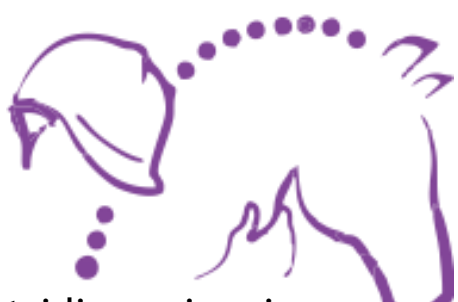
terapêutico que utiliza o cavalo para estimular o desenvolvimento biopsicossocial proporcionando movimentos rítmicos, precisos e tridimensionais com a andadura do cavalo e pode trazer muitos benefícios ao paciente, exigindo a participação integral do corpo, regulando o tônus muscular, facilitando o desenvolvimento de controle postural, força muscular, coordenação motora, dissociação de cinturas, equilíbrio, propriocepção, autoconfiança e autoestima. 


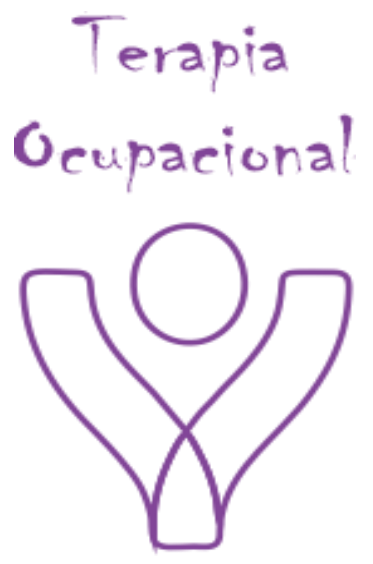

A Terapia Ocupacional é um campo de conhecimento que promove prevenção, tratamento e reabilitação de pessoas que apresentam quadros de alterações sensoriais, afetivas, motoras, cognitivas, sociais e psicomotoras, alterações essas que são prejudiciais a sua qualidade de vida, visando assim auxiliar tais pessoas a terem independência e autonomia na realização de suas atividades de vida diária e instrumentais, melhorando assim suas habilidades de desempenho ocupacional favorecendo seu desenvolvimento em diversos âmbitos. Essa terapia compreende a atividade humana como um processo criativo, criador, lúdico, expressivo, evolutivo, produtivo e de auto manutenção. 


\section{MONITORAMENTO COM ESTUDOS DE CASOS}

O estudo de caso é um método de pesquisa estruturado, que pode ser aplicado em distintas situações para contribuir com o conhecimento dos fenômenos individuais ou grupais objetivando explorar, descrever e explicar o evento ou fornecer uma compreensão profunda do fenômeno. Os

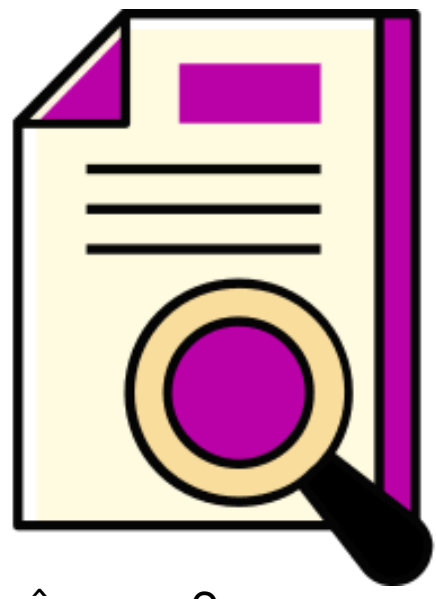
estudos de caso podem ser entendidos ainda como um sistema delimitado e enfatiza, simultaneamente, a unidade e a globalidade desse sistema, requerem dos pesquisadores cuidados com o desenho do protocolo, explicando os procedimentos formais e reconhecendo pontos fortes e limitações do estudo (ANDRADRE et al., 2017).

A escolha por este método para auxiliar os profissionais do NAIIJ/ESAB é apropriada para a busca de respostas pelas demandas específicas de cada paciente que será visto de forma global contemplando todas especialidades terapêuticas e/ou clínicas que está sendo atendido de forma singular para explicar as circunstâncias de sua evolução clínica e projeções para formulação e reavaliação do seu Projeto Terapêutico Singular. 


\section{DEVOLUTIVA PARA AS FAMÍLIAS}

A família é o princípio de todo ser humano, por isso indispensável, pois é nesse meio que se terá os primeiros contatos com a vida em sociedade, que se exteriorizarão as emoções e aprender-se-á sobre a vida. "A base de tudo é a família e nesta deve repousar qualquer linha primeira de ação" (FELIPE, 2000).

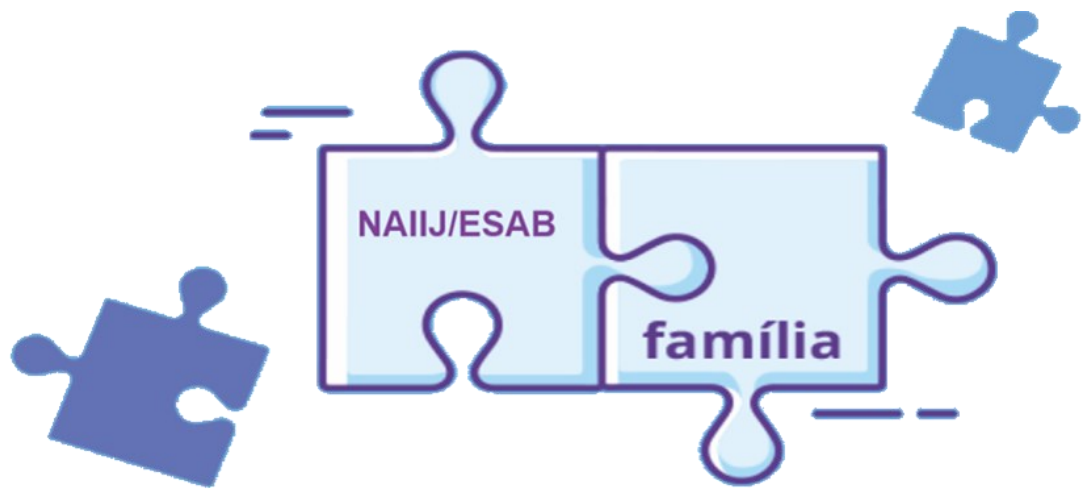

As famílias são parte decisiva no processo de acompanhamento dos pacientes no NAIIJ/ESAB. A Coordenação estará em contato direto com a família e escolas quando necessário para instrumentalizá-las capacitando para que se sinta apta na participação dos cuidados em relação a seus filhos. A cada estudo de caso a Coordenação do NAllJ transmitirá a família a evolução clínica do paciente, não excluindo a possibilidade de haver contato direto com o profissional com o agendamento prévio. 


\section{ESCOLA DE PAIS E APLICADORES (EPA/ESAB)}

O Espaço de Saúde Aline Bispo (ESAB) em parceria com a Legere Consultoria Educacional e Editora apresentam a Comunidade Conquistense e Região Sudoeste da Bahia um espaço destinado à capacitação de pais, educadores, profissionais e cuidadores de crianças especiais. Nesse espaço formativo serão ofertados cursos de qualificação com foco específico nas demandas dos pacientes atendidos no ESAB. Esses cursos serão presenciais cumprindo todas medidas sanitárias de segurança e terão duração média de 20 e 40 horas com emissão de certificados ao final.

$\mathrm{Na}$ execução da metodologia serão aplicados métodos e técnicas que favoreçam a compreensão do conteúdo apresentado contemplando sempre as demandas específicas de cada paciente. Esses cursos serão ofertados em horários previamente agendados que possibilite aos pais e responsáveis uma qualificação que auxiliem na produção de cuidado de seus filhos.

Como Projeto Piloto a EPA/ESAB estará ofertando o Curso sobre "Condutas com crianças e adolescentes na atualidade" que vem responder a uma demanda global de capacitação presencial de curta duração na Região Sudoeste da Bahia. O Curso será ofertado com a carga horária de $40 \mathrm{~h}$, tendo como público prioritário os pais de 
pacientes do NAIIJ/ESAB e também abertos à comunidade. Nesse projeto piloto serão ofertados os seguintes módulos que poderão ser feitos conjuntamente ou separados.

$\checkmark$ Uso excessivo de telas por crianças adolescentes.

$\checkmark$ Importância da Socilalização e prática esportiva para o desenvolvimento.

$\checkmark$ Desenvolvimento de habilidades específicas de aprendizagem.

$\checkmark$ Sexualidade precoce em crianças e adolescentes.

$\checkmark$ Manejo de birras e comportamentos bizarros em crianças e adolescentes.

$\checkmark$ Prevenção do Bullying em crianças e adolesncentes nos contextos virtual e presencial.

$\checkmark$ Reconhecendo sinais de alertas nas novas formas de comunicação com uso da linguagem virtual por crianças e adolescente.

$\checkmark \quad 0$ desfralde e o tempo da criança.

Outros temas serão sugeridos pelos pais, cuidadores, professores e pacientes do NAIIJ/ESAB.
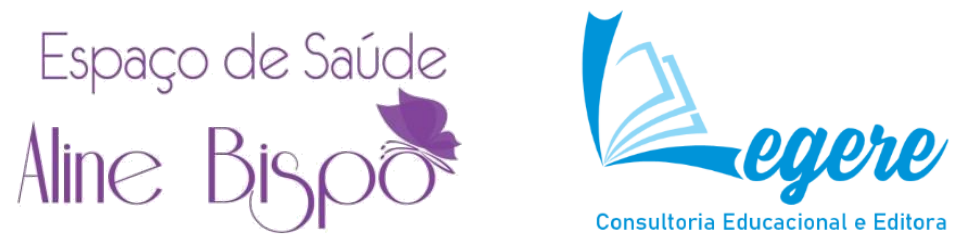


\section{APLICATIVO ESAB $24 \mathrm{H}$}

A clínica ampliada se propõe qualificar o modo de se fazer saúde. Ampliar a

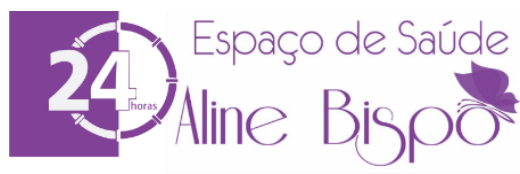
clínica é aumentar a autonomia do usuário do serviço de saúde, da família e da comunidade. É nesse sentido mesmo, de fazer do cotidiano, do trabalho em ato, um espaço de formação de sujeitos críticos e participativos que caminha a Clínica Ampliada. Para tanto, será disponibilizado um aplicativo para profissionais e pais/responsáveis por crianças e adolescentes que atendidos no Espaço de Saúde Aline Bispo no sentido de favorecer a continuidade dos procedimentos terapêuticos e clínicos que podem ser reproduzidos no ambiente doméstico e escolar.

Essa aplicativo favorecerá o compartilhamento de saberes entre os profissionais da equipe multidisciplinar inserindo as famílias e escolas no contexto de habilitação e reabilitação cognitiva, motora, neurológica, social e emocional de crianças e adolescentes atendidos no Espaço de Saúde Aline Bispo. E poderá ampliar o repertório de ações que crianças e adolescentes podem realizar com intervenções precoce, respeitando 0 tempo de desenvolvimento de cada paciente.

Cada profissional após o período de avaliação e diagnóstico do paciente poderá disponibilizar no aplicativo, atividades que podem auxiliar e ampliar o repertório de atividades que estimulem o desenvolvimento de habilidades conforme sua área de atuação. Nesse aplicativo os pais terão acesso às atividades indicadas e após aplicar poderão dar devolutivas sobre a(s) resposta(s) do paciente aos estímulos indicados. Nestas respostas além da parte textual os pais poderão enviar fotos ou mesmo pequenos vídeos (no máximo 03 minutos) de situações que ele não sabe como lidar. 


\section{REFERÊNCIAS}

CECÍLIO, L.C.O. As necessidades de saúde como conceito estruturante na luta pela integralidade e equidade integralidade na atenção e no cuidado à saúde. In: 5PINHEIRO, R.; MATTOS, R.A. (Orgs.). Os sentidos da integralidade na atenção e no cuidado à saúde. Rio de Janeiro: UERJ; IMS; ABRASCO, 2001.

FELIPE, J. Franklin Alves. Adoção, guarda, investigação de paternidade e concubinato. 10. ed. Rio de Janeiro: Forense, 2000.

TELESI, Emílio. Práticas integrativas e complementares em saúde, uma nova eficácia para o SUS. Estudos Avançados [online]. 2016, v. 30, n. 86 [Acessado 25 Agosto 2021] , pp. 99-112. Disponível em: <https: / / doi.org/10.1590/S0103-40142016.00100007>. ISSN 1806-9592. https://doi.org/10.1590/S010340142016.00100007. 


\section{ANEXOS}

\section{ENTREVISTA DE ACOLHIMENTO}

Profissional:

Data:

Nome do paciente:

Idade:

Data de nascimento:

l

Convênio(s):

Mãe: idade:

Estado civil: escolaridade:

Local de trabalho: Profissão:

Cell: e-mail:

Pai: idade:

Estado civil: escolaridade:

Local de trabalho: Profissão:

Cell: e-mail:

Religião praticante: A criança mora com:

Relacionamento dos pais: $\square$ afetuosos $\square$ distantes $\square$ excesso de brigas $\square$ super protetores $\square$ autoritários $\square$ fazem comparações entre os filhos:

Relacionamento com a família: participativo $\square$ distante $\square$ isola-se $\square$ Tipo de personalidade da criança: $\square$ agressiva $\square$ passiva $\square$ tímida Extrovertida $\square$ ansiosa $\square$ depressiva $\square$

Comportamento de roer unhas $\square$ chupar dedos $\square$ tiques $\square$ manias qual atitude tomada diante desses hábitos

há casos de doenças mentais nos antecedentes familiares $\square \operatorname{Sim} \square$ Não Grau de parentesco:

Algum membro da família faz (ou fez) tratamento $\square \operatorname{Sim} \square$ Não 
Dorme em quarto sozinho: com os pais: com os irmãos:

Tem horários para dormir Dorme que horas à noite: quantas horas por dia:

Tipo de sono: $\square$ Tranquilo $\square$ agitado $\square$ interrompido

$\square$ Conversa durante o sono $\square$ sonambulismo $\square$ Fobias noturnas $\square$ gritos

$\square$ range os dentes $\square$ pesadelos constantes

A criança tem medo de alguma coisa, objeto, animal em excesso:

Tipo de linguagem: fácil entendimento: difícil entendimento:

Troca letras $\square$ sim $\square$ não quais:__ Compreende as palavras: $\square$ sim $\square$ não Toma algum remédio diariamente: $\square \operatorname{sim} \square$ não qual:

Possui problemas respiratórios: $\square$ asmas $\square$ Bronquites $\square$ outros:

Tem alergias a algum objeto, pelos, etc: $\square \operatorname{sim} \square$ não

Costuma ter desmaios: $\square$ sim $\square$ não desânimos: $\square$ sim $\square$ não Já houve fraturas: $\square \operatorname{sim} \square$ não idade: __ qual membro:

Visão: enxerga bem: $\square \operatorname{sim} \square$ não já consultou um oftlamo: $\square \operatorname{sim} \square$ não Audição: problemas (desde quando) qual ouvido:

Pediatra da criança: Fone:

Gosta de assistir televisão: $\square \operatorname{sim} \square$ não Que programas:

Quantas horas por dia assiste TV: Assiste TV até que hora da noite: Gosta de passear: qual suas preferências: Faz coleções:

Demonstra interesse por instrumento musical:

Os pais costumam contar que tipos de histórias:

Escola ou creche

Entrou com que idade: Gosta de cantar: : $\square \operatorname{sim} \square$ não gosta de histórias: $\square \operatorname{sim} \square$ não

Pratica algum esporte: : $\square \operatorname{sim} \square$ não Qual(ais): 
Observações:

\section{ESPECIALIDADES TERERAPEUTICAS}

$\square$ Arteterapia

$\square$ Natação

$\square$ Hidroginástica

$\square$ Personal Kids

$\square$ Pet-terapia

$\square$ Musicoterapia

\section{ESPECIALIDADES CLÍNICAS}

$\square$ Fonoaudiologia

$\square$ Musicoterapia

$\square$ Psicopedagogia

$\square$ Psicomotricidade

$\square$ Psicologia

$\square$ Nutrição

$\square$ Fisioterapia

$\square$ Terapia Ocupacional

$\square$ Neuropsicologia

$\square$ Equoterapia 


\title{
TERMO DE COMPROMISSO DOS PAIS E RESPONSÁVEIS
}

\author{
TERMO DE COMPROMISSO DE ATENDIMENTO \\ E CONSENTIMENTO LIVRE E ESCLARECIDO
}

Por meio deste documento torna ciente o (a) Sr.(a). pelo responsável menor

sobre as normas e condições do atendimento avaliativo e terapêutico no Núcleo de Atendimento Integral Infanto Juvenil do Espaço de Saúde Aline Bispo (NAllJ/ESAB).

1. ATENDIMENTO: o atendimento multidisciplinar será realizado pelo(a) profissional habilitado $e$ competente, devidamente registrado nos Conselhos Regionais Profissionais.

2. CRONOGRAMA DE ATENDIMENTO: o atendimento acompanha o calendário de dias úteis e horários fixos semanais, de acordo com a determinação do(a) terapeuta.

3. FALTAS: será permitido ao paciente duas faltas justificadas durante o semestre de atendimento. No caso de uma terceira falta, justificada ou não, o paciente receberá um contato da recepção para verificar os motivos e realizar os ajustes para um novo agendamento conforme disponibilidade do profissional e da família. 
4. ATRASO: em caso de atraso do paciente, o atendimento ficará comprometido se exceder o período de dez (10) minutos. Caso sejam verificados atrasos frequentes no decorrer do mês, a recepção irá informar a Coordenação do NAllJ que deverá buscar uma melhor forma para realizar a mudança de dia ou horário conforme disponibilidade da agenda de marcação.

5. TEMPO DE SESSÃO: cabe ao terapeuta, que atende o paciente, estar presente aos atendimentos, no horário estipulado. 0 atendimento é em média 30 minutos por sessão. Quando houver necessidade dos pais falarem com o terapeuta deverão informar a recepção para o devido agendamento prévio e informação ao profissional. Em caso de falta do terapeuta o paciente será informado, com antecedência e o atendimento reposto se possível para as duas partes.

Declaro que, após ter sido devidamente esclarecido e ter entendido o que me foi explicado, concordo com as normas de atendimento do Espaço de Saúde Aline Bispo.

Vitória da Conquista-BA, I__ Assinatura do responsável: 



\section{Av. Jonas Hortélio, $N^{\circ} 781$, Bairro: Recreio Av. Otávio Santos, №30, Bairro: Recreio,$$
\text { Tel.: (77) 3421-8010 }
$$$$
\text { VITÓRIA DA CONQUISTA- BA }
$$

\section{http://espacodesaudealinebispo.com.br}

\section{(7) (77) 98803.5005}

@ administracao@espacodesaudealinebispo.com.br

(0) @espacoalinebispo

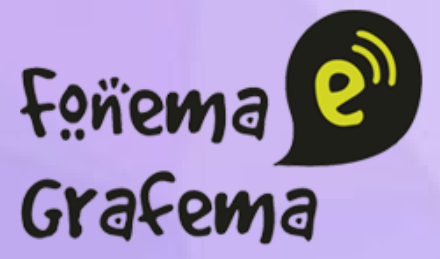

